To be presented at Microscopy \& Microanalysis 98

Atlanta, Georgia, July 12-16, 1998, and published in Proceedings

\title{
Atomic Structures of Inversion Domain Boundaries and Dislocations in Sintered AlN
}

Y. Yan, M. F. Chisholm, and S. J. Pennycook

Solid State Division, Oak Ridge National Laboratory

P.O. Box 2008, Oak Ridge, Tennessee 37831-6030

prepared by

SOLID STATE DIVISION

OAK RIDGE NATIONAL LABORATORY

Managed by Managed by
LOCKHEED MARTIN ENERGY RESEARCH CORP.
under

Contract No. DE-AC05-96OR22464

with the

U.S. DEPARTMENT OF ENERGY

Oak Ridge, Tennessee

February 1998 


\section{DISCLAIMER}

This report was prepared as an account of work sponsored by an agency of the United States Government. Neither the United States Government nor any agency thereof, nor any of their employees, makes any warranty, express or implied, or assumes any legal liability or responsibility for the accuracy, completeness, or usefulness of any information, apparatus, product, or process disclosed, or represents that its use would not infringe privately owned rights. Reference herein to any specific commercial product, process, or service by trade name, trademark, manufacturer, or otherwise does not necessarily constitute or imply its endorsement, recommendation, or favoring by the United States Government or any agency thereof. The views and opinions of authors expressed herein do not necessarily state or reflect those of the United States Government or any agency thereof. 


\title{
ATOMIC STRUCTURES OF INVERSION DOMAIN BOUNDARIES AND DISLOCATIONS IN SINTERED ALN
}

\author{
Yanfa Yan, M. F. Chisholm and S. J. Pennycook \\ Solid State Division, Oak Ridge National Laboratory, Oak Ridge, Tennessee 37831-6030
}

AlN is an attractive material because of its mechanical, thermal and electronic properties. However, these properties are often adversely altered by extended defects such as inversion domain boundaries (IDBs), and through impurities associated with the defects, especially oxygen. Thus to improve the properties of the material it is important to understand the structures of the defects. A number of studies have been carried out to characterize these defects using fringe contrast, weak-beam, convergent-beam electron diffraction and conventional high-resolution phase contrast imaging. ${ }^{1-5}$ These techniques all require the use of model structures for data interpretation. In this paper, we report a direct determination of the structures of IDBs and dislocation cores in AlN by highresolution Z-contrast imaging using a $300 \mathrm{kV}$ VG HB603U scanning transmission electron microscope, with a probe size of $1.3 \AA$.

In sintered AlN, two types of IDBs are observed, a flat IDB lying on the (0001) basal plane and a curved IDB with no preferred habit plane. Fig. 1 shows a Z-contrast image of a flat IDB along [1120] zone axis and the projected structure derived from the image. The distance between an Al column and its nearest $\mathrm{N}$ column in the bulk in this projection is only $1.09 \AA$; hence they cannot be resolved, but the bright Al columns in the Z-contrast image clearly have an elongated shape due to the two closely spaced columns. From the presence of bright spots at the boundary it is immediately seen that the boundary terminates at the $\mathrm{Al}(0001)$ plane. These features are elongated more than in the bulk crystal, consistent with the presence of two adjacent $\mathrm{N}$ columns. The direction of elongation shows the arrangement of these two $\mathrm{N}$ columns. A schematic of the structure derived directly from the image is seen in Fig. 1(b). The doted lines denote two unit cells in each domain, related by an inversion operation. The polarities of the two domains adjoining to the flat IDB have a head-to-head configuration, which is consistent with the result determined by CBED techniques ${ }^{5}$. It is known that flat IDBs are associated with oxygen impurities. Oxygen atoms may substitute for nitrogen atoms at the boundary to form a single octahedral Al-O layer. Our first-principles calculations confirm that this replacement causes an expansion at the boundary. This expansion is directly visible in the Z-contrast image. The expansion at the IDB is $0.3( \pm 0.2) \AA$, consistent with the first-principles calculations.

The flat and curved IDBs often join to form dome-like defects. In this case, they are always connected by a dislocation. Fig. 2 shows the Z-contrast image of such a dislocation along [1120] zone axis. It is clearly seen that there is an extra (0001) plane at the dislocation. The core structure of the dislocation is deduced directly from the image.

\section{Reference}

1. R.A. Youngman and J.H. Harris, J. Am. Ceram. Soc. 73, (1990)3223.

2. A. Berger, J. Am. Ceram. Soc. 74, (1991)1148, ibid., 78, (1995)153.

3. A.D. Westwood and M.R. Notis, J. Am. Ceram. Soc. 74, (1991)1226; A.D. Westwood et al. J. Mater. Res., 10, (1995)1270, ibid., 10, (1995) 1287.

4. M.R. McCartney, R.A. Youngman and E.G. Teller, Ultramicroscopy, 40, (1992)291.

5. Y. Yan, M. Terauchi and M. Tanaka, Phil. Mag. A75, (1997)1005.

6. This research was sponsored by the Division of Materials Sciences, U.S. Department of Energy, under contract DE-AC05-96OR22464 with Lockheed Martin Energy Research Corporation, and by appointment to the ORNL Postdoctoral Research Program administered jointly by ORISE and ORNL. The authors thank Prof. M. Tanaka and Dr. Terauchi at Tohoku University, Japan for supplying AlN crystals. 


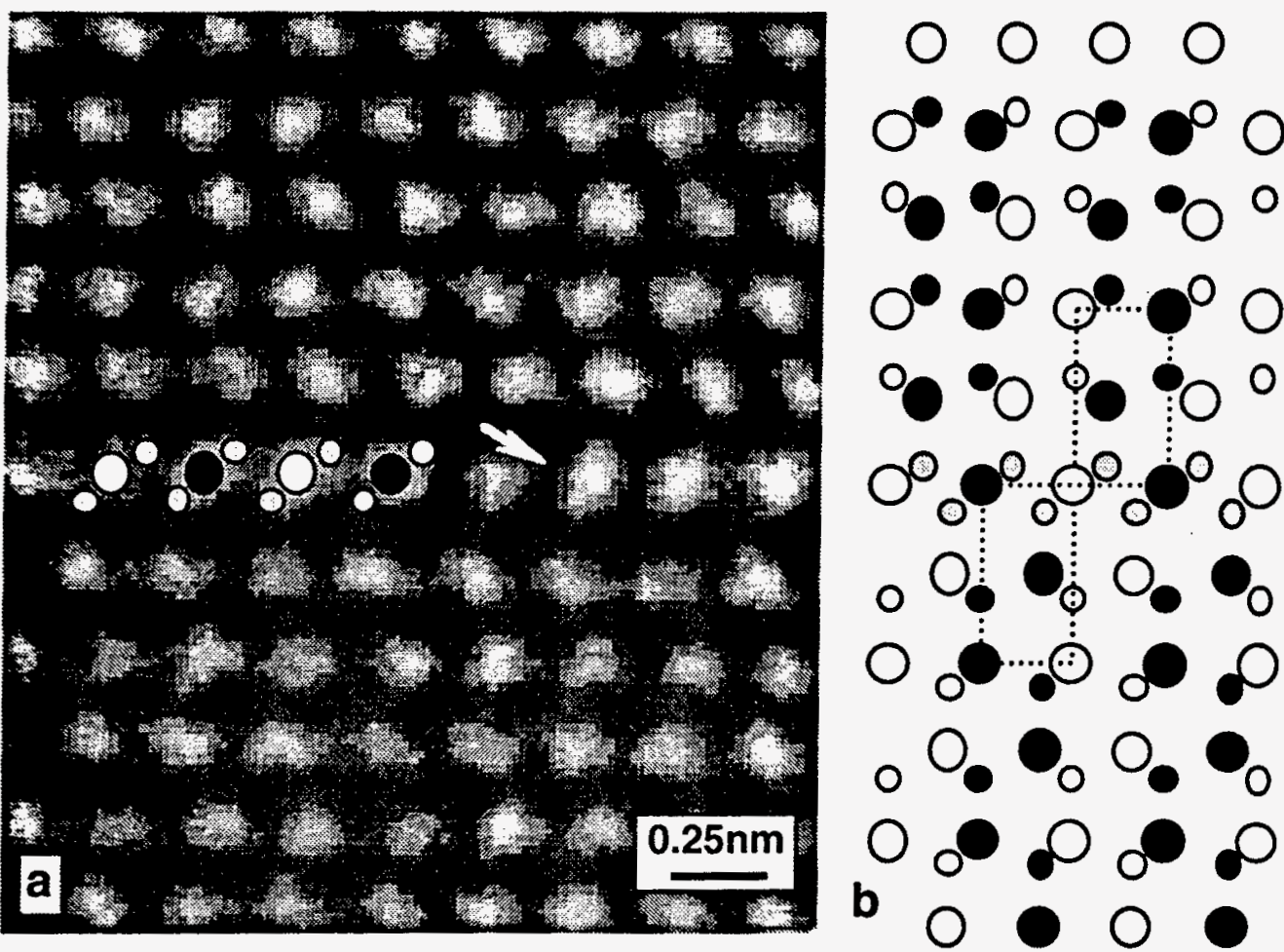

FIG. 1. (a) High-resolution Z-contrast image of a flat inversion domain boundary in sintered AIN. (b) the boundary structure derived from the image.

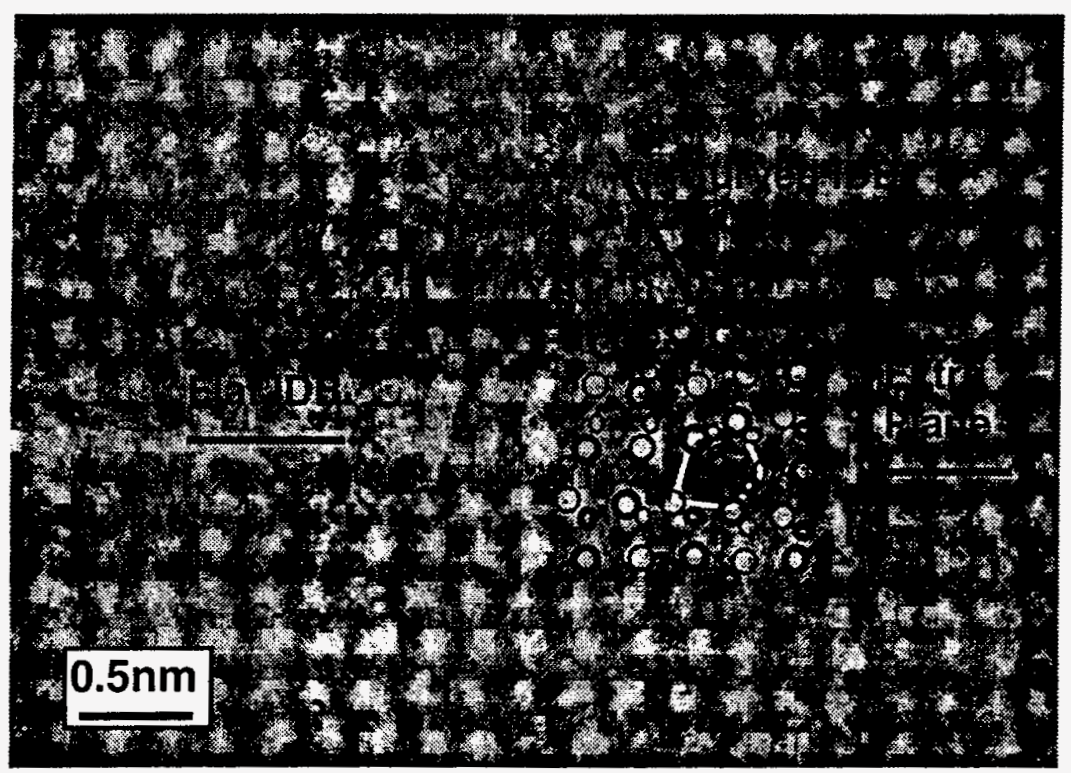

FIG. 2. High-resolution Z-contrast image of a dislocation core connecting a flat and a curved inversion domain boundary. The positions of inversion domain boundaries, the extra (0001) plane and the dislocation core structure are indicated. 

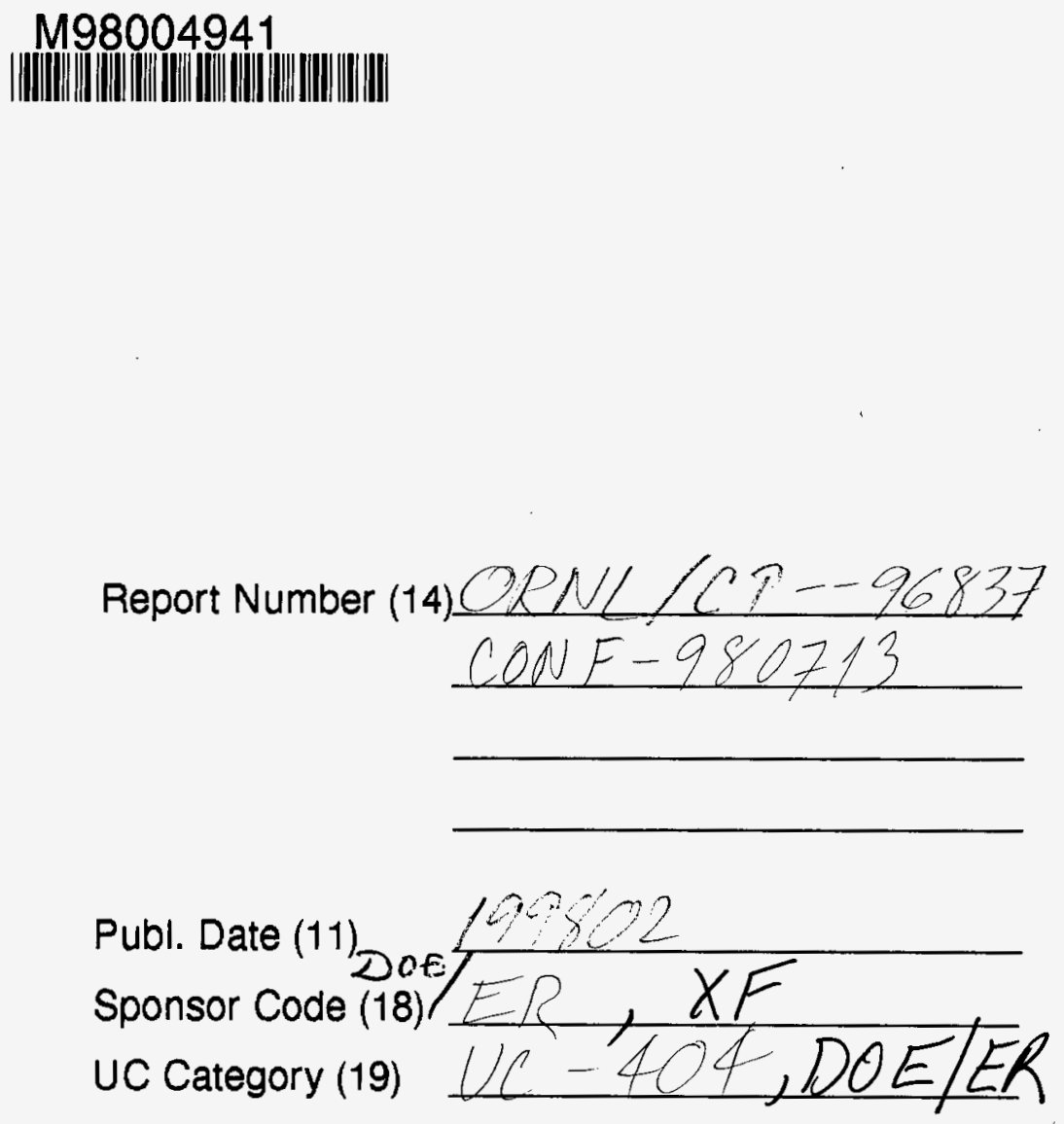